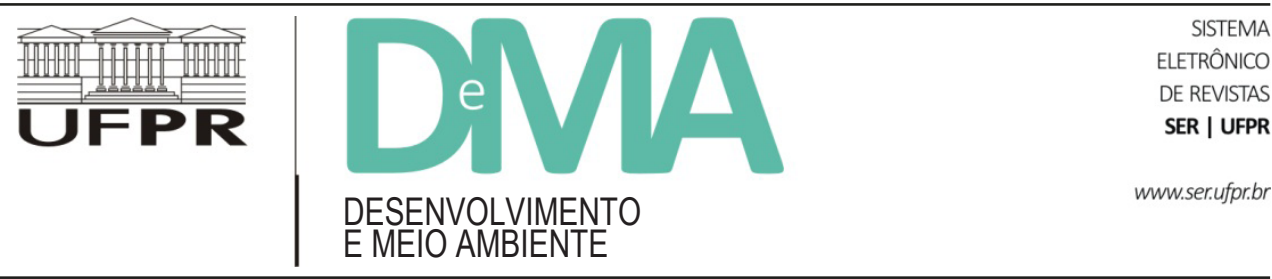

\title{
Das colonialidades à emergência de um novo paradigma no Semiárido brasileiro desde as racionalidades camponesas: um caminhar para além do desenvolvimento?
}

\section{From colonialities to the emergence of a new paradigm in the Brazilian Semiarid since peasant rationalities: a journey beyond development?}

\author{
Valcilene Rodrigues da SILVA ${ }^{1 *}$, Mônica Cox de Britto PEREIRA ${ }^{2}$ \\ ${ }^{1}$ Universidade Federal de Pernambuco, Recife, Pernambuco, Brasil. \\ ${ }^{2}$ Departamento de Ciências Geográficas, Universidade Federal de Pernambuco, Recife, PE, Brasil. \\ *E-mail de contato: valcilener@gmail.com
}

Artigo recebido em 18 de maio de 2020, versão final aceita em 20 de outubro de 2020, publicado em 18 de dezembro de 2020.

RESUMO: As teorias pós-coloniais e descoloniais vêm nas últimas décadas questionando o paradigma da modernidade e o modelo de desenvolvimento atual. No que se refere ao Semiárido brasileiro, as colonialidades se expressam por meio de diferentes fenômenos ou contextos, como os do campo discursivo, do coronelismo, da indústria da seca, do processo de modernização agrícola, das relações de gênero e dos processos educativos. No entanto, apesar de tais colonialidades, os(as) camponeses(as) do Semiárido vivem em resistência para se manterem no campo desde seu modo de vida. A pesquisa tem como objetivo analisar o contexto de colonialidades no Semiárido, bem como os processos de resistência e aprendizado com a natureza que apontam para a emergência de um paradigma de convivência. Dentre as diversas estratégias analisadas, destacam-se os processos de organização e mobilização social, a educação e a comunicação popular, economias solidárias, tecnologias sociais, pluriatividade, festas e diversos conhecimentos tradicionais que garantem a esses sujeitos a permanência no campo e a ampliação de sua autonomia. Conclui-se que o paradigma da convivência aponta para a possibilidade de o Semiárido caminhar para além do desenvolvimento. Essa perspectiva é chave importante para a resistência em relação aos processos de colonialidade do poder, do saber, do ser e da natureza presentes na realidade semiárida.

Palavras-chave: agricultura camponesa; campesinato; descolonização; pós-desenvolvimento; decolonialidade. 
ABSTRACT: Postcolonial and decolonial theories have been questioning the paradigm of modernity and the current development model in recent decades. Regarding the Brazilian Semiarid, colonialities are expressed through different phenomena or contexts, such as those in the discursive field, "coronelismo", the drought industry, the agricultural modernization process, gender relations and educational processes. However, despite such colonialities, the semiarid peasants live in resistance to remain in the countryside through their way of life. This research aims to analyze the context of colonialities in the Semi-Arid, as well as the processes of resistance and learning with nature which point to the emergence of a paradigm of coexistence. Among the various strategies analyzed, we highlight the processes of organization and social mobilization, education and popular communication, solidarity economies, social technologies, pluriactivity, parties and various traditional knowledge that guarantee to these subjects the permanence in the field and the expansion of their autonomy. It is concluded that the coexistence paradigm points to the possibility of the semiarid to go beyond development. This perspective is an important key to the resistance in relation to the coloniality processes of power, knowledge, being and nature, present in the semi-arid reality.

Keywords: peasant agriculture; peasantry; decolonization; post-development; decoloniality.

\section{Introdução}

As teorias pós-coloniais e descoloniais vêm nas últimas décadas questionando a lógica colonial-moderno-capitalista, bem como o modelo de desenvolvimento atual (Quijano, 1992; Escobar, 1995; Quijano, 2005; González-Casanova, 2007; Quijano, 2007; Escobar, 2014; Acosta, 2016; Lang, 2016; Gudynas, 2017, Mignolo, 2017). Quando se analisa o contexto brasileiro, sabe-se que o território foi invadido pelos portugueses no século XVI, tendo resultado em desapropriação e destruição em massa da população indígena.

Especialmente no Semiárido, nota-se que o processo de ocupação foi marcado por violências e desigualdades sociais que vão desde a expropriação de terras indígenas ao regime de escravidão da lavoura canavieira ou, posteriormente, à figura do meeiro, posseiro ou sitiante nas grandes fazendas (Andrade, 1988).

Manuel Correia de Andrade (1988) aponta ainda que ao longo do tempo foi surgindo uma camada intermediária entre latifundiários e mão de obra escrava. Essa população, no campo, tinha numerosas e diversificadas culturas feitas em terras alheias ou em pequenas porções de terras próprias, visando ao autoabastecimento e à venda para as vilas. Sobre essa camada, o autor afirmou ser o germe de um campesinato no Nordeste (Andrade, 1987) que já nascia num contexto de resistência e invisibilidade.

Historicamente o Semiárido foi "esquecido" pelo Estado e, por conseguinte, desassistido pelas políticas públicas. A ocupação e a exploração dos bens naturais aconteciam para atender às necessidades da Coroa e, posteriormente, de uma elite litorânea, desconsiderando os sujeitos que viviam na região. Albuquerque Júnior (1999, p. 13) afirma que, até meados de 1910, o Nordeste sequer existia. As elites locais não se mobilizavam "[...] para resolver o problema de falta de chuvas, da gente e do gado que morriam de fome e de sede". O problema mal era anunciado, era apenas vivido por sua gente.

Para o autor, o Nordeste tal como se encontra na literatura não existiu desde sempre. A produção desse lugar foi criada ao longo de décadas e com 
base em diferentes discursos que lhe atribuíram determinadas características físicas e investiram em inúmeros atributos morais, culturais e simbólicos. "A ideia de Nordeste foi construída designando-o na maior parte das vezes de forma pejorativa, como lugar do atraso, do rural e do passado persistente, valorizando em contrapartida o Sudeste e o Sul agilizados como espaços do progresso, da razão e do futuro" (Andrade, 1987, p. 14).

Carlos Walter Porto-Gonçalves corrobora essa ideia quando afirma que "no Brasil, há o nordestino, o sulista e o nortista, mas não há o sudestino, nem o centro-oestista. Afinal, o Sudeste é o centro e, como tal, não é parte. É o todo!". Assim, se compreende que a melhor forma de dominação, de colonialidade é aquela que, naturalizada, não aparece como tal (Porto-Gonçalves, 2005, p. 3).

A elaboração intelectual do processo de modernidade produziu uma perspectiva de conhecimento e um modo de produzir conhecimento que demonstra o caráter do padrão mundial de poder: colonial-moderno-capitalista e eurocentrado. Isto é, a imposição de certos grupos e de certos saberes sobre os demais (González-Casanova, 2007; Santos, 2018).

No entanto, apesar de tal contexto, camponesas e camponeses, historicamente invisibilizados e marginalizados, vivem em resistência para se manterem no campo desde seu modo de vida. Assim, o artigo, que é um recorte de um estudo de doutoramento em andamento, tem como objetivo analisar o contexto de colonialidades no Semiárido, bem como os processos de resistência e aprendizado com a natureza que apontam para a emergência de um paradigma de convivência com essa realidade.

Metodologicamente, buscaram-se respostas para o estudo a partir das sociologias das ausências e sociologias das emergências propostas por Boaventura de Sousa Santos (2018) para compreender qual é o Semiárido que está sendo pautado e a partir de que visão de mundo. Desde a sociologia das ausências, procurou-se enxergar como as colonialidades operam para produzir exclusões abissais no Semiárido, isto é, para produzir certos grupos de pessoas e formas de vida social como não existentes, invisíveis, inferiores ou perigosos. Por meio da Sociologia das emergências, buscou-se evidenciar a valorização simbólica e política das formas de ser, saber e viver no Semiárido que se apresentam do outro lado da linha abissal.

Nessa perspectiva, além de uma vasta revisão bibliográfica, foram realizadas entrevistas abertas com 13 sujeitos sociais coletivos que compõem o Movimento Agroecológico no Semiárido de Pernambuco e duas oficinas, seguidas de rodas de conversas com camponeses(as) de duas comunidades rurais de Brejinho-PE, Comunidade Caldeirão e Comunidade Vila de Fátima. A análise dos dados se deu de forma qualitativa, valendo-se de categorias significativas para compreender as relações de colonialidades e estratégias de resistências na realidade em causa.

\section{Processo de ocupação colonial e as múltiplas colonialidades no Semiárido brasileiro das Caaatingas Brasileiras}

A existência humana em território nordestino é anterior à colonização portuguesa. Diversos trabalhos confirmam esse fato, como os estudos desenvolvidos pela arqueologia, na Serra da Capivara, Estado do Piauí (Guidon \& Delibrias, 1986; Guidon et al., 1994), em que se apontam 
evidências de presença humana na região que datam de 60.000 anos.

De acordo com Dantas et al. (1992), grupos de etnia não tupi, de diversas famílias linguísticas, dominavam os sertões da Caatinga, onde se destacava a grande família kariri, que ocupava os sertões desde o Ceará até a Bahia. Entretanto, o processo de ocupação portuguesa trouxe mudanças drásticas para a região. Além do violento extermínio indígena e das enfermidades, esse processo impôs sua ideologia ao introduzir equipamentos tecnológicos, animais e plantas e ao destruir a cultura e a língua nativas. Etchevarne (2000, p. 128) afirma que "a ocupação portuguesa do território nordestino pode ser considerada um divisor de águas, em termos cronológicos, pelo impacto provocado no universo das sociedades indígenas".

Conforme Haroldo Schistek (2013), a partir dos anos 1640, os currais de gado bovino foram levados ao Sertão, onde iniciaram uma política concebida de fora para dentro que desconsiderava as características da região e do seu povo e servia aos interesses da Coroa ou da elite litorânea.

Manuel Correia de Andrade (2004) afirma que em apenas um século todo o Sertão do Nordeste foi apropriado, formaram-se grandes fazendas, com centenas de léguas de extensão. Os índios vencidos não tiveram outra escolha e transformaram-se em força de trabalho para os fazendeiros, seja no cuidado com o gado, no cuidado doméstico ou nas culturas alimentares.

Desde esse período, a dominação social da terra configura complexos problemas, como o predomínio do latifúndio, a dificuldade dos(as) camponeses(as) em ter o acesso e a posse da terra, a degradação dos bens naturais e ausência de políticas públicas voltadas para os(as) camponeses(as). Ou seja, acabou a colonização portuguesa histórica, mas permaneceram em seu lugar o colonialismo interno e diversas colonialidades (Quijano, 1992; 2007).

Convém destacar que a noção de colonialismo e colonialidade utilizada na pesquisa é aquela defendida por Aníbal Quijano. Entende-se por colonialismo a relação de dominação direta, política, social e cultural dos europeus sobre os "conquistados" de todos os continentes (Quijano, 1992).

Conforme Ives Chaloult (1978, p. 36), “durante séculos, as colônias foram um poderoso símbolo de riqueza, poder e dominação para as metrópoles", mas as relações coloniais se internalizaram no decorrer do tempo. González-Casanova (2007) vai chamar esse processo de colonialismo interno, em que sai de cena a dominação direta do estrangeiro sobre os nativos e emerge a exploração de nativos por nativos.

Nesse sentido, Quijano (1992) pontua que o colonialismo como ordem política explícita foi destruído, entretanto, não desapareceu com a independência dos países. $\mathrm{O}$ autor usa a noção de colonialidade ao invés de colonialismo interno por entender a colonialidade como um conceito diferente, ainda que vinculado ao de colonialismo.

Para o autor,

A colonialidade é um dos elementos constitutivos e específicos do padrão mundial do poder capitalista. Baseia-se na imposição de uma classificação racial/ étnica da população do mundo como pedra angular desse padrão de poder e opera em cada um dos planos, áreas e dimensões, materiais e subjetivos, da existência cotidiana e em escala social (Quijano, 2007, p. 93). 
Assim, a colonialidade é a classificação social baseada na noção de raça, que tem origem no caráter colonial, mas transcende as singularidades do colonialismo. É o modo mais geral de dominação da atualidade (Quijano, 1992; 2005; 2007) e é constitutiva da modernidade ou o lado mais escuro da modernidade (Mignolo, 2017). "Ela se mantém viva em textos didáticos, nos critérios para o bom trabalho acadêmico, na cultura, no sentido comum, na autoimagem dos povos, nas aspirações dos sujeitos e em muitos outros aspectos de nossa experiência moderna" (Maldonado-Torres, 2007, p. 131).

De modo geral, a colonialidade é estabelecida valendo-se de quatro bases principais: colonialidade do poder, colonialidade do saber, colonialidade do ser (Quijano, 2005; Lander, 2005; Castro-Gómez, 2007) e colonialidade da natureza (Walsh, 2008).

Ao analisar o campesinato do Semiárido brasileiro, percebem-se tais colonialidades presentes em diferentes fenômenos ou contextos. Neste texto, destacam-se as colonialidades do campo discursivo, do coronelismo, da indústria da seca, do processo de modernização agrícola, das relações de gênero e dos processos educativos.

\subsection{Colonialidade da realidade pelo discurso}

De acordo com Albuquerque Júnior (1999), o Nordeste e o nordestino são "invenções" ou resultados de determinadas relações de poder e de saber no campo discursivo. Para o autor, falar de Nordeste é mobilizar todo o universo de imagens socialmente reconhecidas e consagradas que criaram a ideia de Nordeste - lugar de clima quente e Caatinga seca; gente preguiçosa, improdutiva e violenta; lugar do atraso, fome e miséria.

Em outras palavras, o Nordeste é inventado e contado com base nas diversas colonialidades que criam estereótipos para a região e para os sujeitos que a compõem, especialmente aqueles do meio rural. E, como afirma a escritora nigeriana Chimamanda Adichie, o problema com os estereótipos não é que eles sejam mentirosos, mas que são incompletos (TED, 2009). Além disso, "o estereótipo nasce de uma caracterização grosseira e indiscriminada do grupo estranho, em que as multiplicidades e as diferenças individuais são apagadas, em nome de semelhanças superficiais do grupo" (Albuquerque Júnior, 1999, p. 20).

Ainda de acordo com Albuquerque Júnior (1999, p. 17), são múltiplas e sofisticadas as formas pelas quais o Nordeste foi e é excluído social e culturalmente, por meio de estratégias invisíveis do poder no campo discursivo, "que nos capturam, através das quais somos falados, sem que muitas vezes percebamos suas redes e armadilhas". Logo, para superar o discurso dominante e os estereótipos acerca do Nordeste, se faz necessário entender as relações de poder e de saber que produziram as imagens a respeito deste Nordeste.

Os discursos nos quais se afirma a necessidade de acabar com o limite da semiaridez e combater a seca, por exemplo, se materializaram na indústria da seca, uma colonialidade que "gerou a concentração da terra, da água, do saber, do poder e o aumento crescente da fome e da miséria no Semiárido" (Baptista \& Campos, 2013a, p. 52), além de beneficiar os grandes latifundiários e incentivar o advento do coronelismo. 
Como a colonialidade do poder se refere aos processos de dominação e/ou repressão sobre as crenças, os modos de produção de conhecimento, os saberes, o mundo simbólico e as imagens do colonizado (Quijano, 1992), percebe-se que os discursos acerca do Nordeste resultam de tal colonialidade. $\mathrm{O}$ efeito nefasto disso se configurou na situação na qual muitas pessoas passaram a acreditar na incapacidade delas próprias, na inviabilidade da região, na imagem de um lugar inóspito por natureza e de seres inferiores (Baptista \& Campos, 2013b). Igualmente, a violência simbólica da colonialidade atua no campo da sedução, em que os sujeitos passam a seguir os critérios e padrões da lógica dominante. Exemplo disso é a suposta necessidade de acabar com o limite da semiaridez entendida como condição para transformar o Nordeste em lugar de prosperidade e de desenvolvimento.

\subsection{Colonialidades originadas do coronelismo}

O coronelismo, expressão tipicamente do Semiárido (Malvezzi, 2007), é um exemplo claro da estrutura triangular da colonialidade: colonialidade do ser, colonialidade do poder e colonialidade do saber (Castro-Gómez, 2007), pois atua nas dimensões econômica, social, política e ideológica (Dantas, 1987) do povo sertanejo.

Ao mencionar o coronelismo como uma forma de colonialidade no Semiárido, convém ressaltar que a pesquisa não teve a pretensão de explicar conceitos como mandonismo, clientelismo e paternalismo, mas problematizar as relações de dominação existentes no fenômeno do coronelismo.
Concorda-se aqui com Waldemar Alves da Silva Júnior (2006, p. 141), quando ele afirma que:

o coronelismo se baseia no controle de alguma forma de poder, seja ele político, através da coerção; ideológico, através do monopólio das informações e que fatalmente legitima toda uma rede de ideias mais ou menos coerentes que reforçam os laços de dominação e dependência pessoal; ou econômico, baseado na posse da terra e no controle das atividades comerciais que ao gerar grande número de empregos na cidade contribuem para a reprodução desses tipos de relações de dominação e dependência pessoal.

Para Leal (2012), o meio rural se constituiu como espaço privilegiado para a incidência do coronelismo, pois apresentava as condições de dominação e de dependência pessoal favoráveis, devido à estrutura agrária baseada no latifúndio.

Esse contexto interferiu historicamente na dimensão econômica e social do sertanejo, pois, como destaca Ibarê Dantas (1987), o latifundiário (coronel) exerce sobre os trabalhadores rurais relações não capitalistas de produção (meação, parceria, foreamento) e um tipo de dominação sob a forma de dependência pessoal (obrigação de lealdade e fidelidade). Assim, por possuir os meios de produção, os coronéis exercem poder sobre sua clientela pobre e dependente e camuflam as desigualdades sociais e as relações de exploração.

Correlacionada às dimensões econômica e social, atua a dimensão ideológica do coronelismo, um conjunto de ideias e representações veiculadas por meio de normas que reforçam os laços de lealdade e as práticas de submissão (Dantas, 1987). Isto é, por um lado, os coronéis estabelecem relações de compadrio e de favores (batizar filho, apadrinhar casamento, arranjar emprego para os filhos do vaqueiro, 
levar a grávida para a maternidade) e conseguem, estrategicamente, a aceitação e o reconhecimento dos(das) camponeses(as) (Leal, 2012). Por outro lado, estabelecem e põem em prática as relações que reprimem violentamente os que ousam divergir do coronel local (Dantas, 1987), uma verdadeira colonialidade do ser.

E, por fim, destaca-se a dimensão política do coronelismo, em que o coronel exerce um papel de intermediário entre as massas do campo e as oligarquias estaduais, com o objetivo de manter a estrutura de dominação (Dantas, 1987). A colonialidade do poder e do ser se concretiza nessa dimensão política, quando o coronel exclui o camponês como sujeito político. De acordo com Silva Júnior (2006), o coronelismo implica a capacidade de manipulação eleitoral das massas do campo, o que dá origem ao conhecido "voto de cabresto", que indica uma limitação dos sujeitos do campo para exercerem livremente o voto.

As colonialidades se transformam e se moldam ao longo da história. Assim, de acordo com Malvezzi (2007), no Estado Novo, o poder dos coronéis foi sendo reduzido. Em decorrência disso, o coronelismo se reinventou, passando de um coronelismo clássico para um coronelismo moderno-eletrônico. Os coronéis modernizados aliaram os meios modernos de comunicação a métodos antigos - favores e repressão - ao montarem impérios comunicativos, especialmente as rádios. Uma estratégia inteligente e perversa para usar a tecnologia a serviço do atraso e da dominação das pessoas.

Atualmente, embora com menos força, as práticas coronelistas ainda estão presentes, especialmente nos municípios menores, em que algumas famílias tradicionais ainda mantêm o poder local, mantêm a indústria da seca e usam as políticas públicas como nova forma de dominação e concentração de poder.

\subsection{Colonialidades originadas da indústria da seca}

A indústria da seca, termo utilizado para designar a exploração política da miséria e a apropriação privada dos recursos públicos pelas oligarquias sertanejas (Silva, 2006), é um bom exemplo de dominação colonial no Semiárido e nasce da lógica de combate à seca (colonialidade da natureza).

A seca é um fenômeno que sempre existiu no Semiárido, mas até metade do século XIX não era levada em conta na agenda governamental. Os povos nativos da região viviam em um regime nômade de vida, convivendo com as estiagens e aproveitando os bens naturais disponíveis, especialmente nas áreas úmidas, como os vales de rios perenes e os brejos de altitude (Silva, 2006). Viviam com seca, mas, sem cercas, logo podiam migrar. Essa realidade mudou com a ocupação dos colonizadores.

De acordo com Silva (2006, p. 38),

\begin{abstract}
Essas áreas foram ocupadas pelos colonizadores, que instalaram as fazendas de gado, resultando em adensamento populacional e maior exploração da terra. A disputa por essas áreas foi fatal para os povos indígenas, que sucumbiram diante da perda da posse das serras, depositárias de caça, de frutas e de água, elementos fundamentais à alimentação. Além disso, a violência foi a principal arma dos colonizadores para ocupar essas terras e colocar os seus rebanhos, portando-se com uma crueldade tal que fizeram um verdadeiro genocídio.
\end{abstract}

Assim, os indígenas que sobreviveram às guerras passaram a viver os flagelos da seca. Não pelo 
fenômeno em si, mas porque foram alocados ao não lugar e ao não sujeito no momento em que foram privados das condições de convivência com seus territórios, instaurando-se, assim, a colonialidade do ser. A seca só passa a ser um problema importante quando atinge a população branca consolidada no Semiárido e os seus rebanhos bovinos, evidenciando a materialização da ideia de raça mencionada por Aníbal Quijano (2005).

De acordo com Albuquerque Júnior (1999), a seca foi descoberta como arma política no discurso regionalista do Nordeste em 1877. O tema da seca deu origem à própria ideia de Nordeste, cuja abrangência se estabelecia em decorrência desse fenômeno. $\mathrm{O}$ discurso da seca mobilizava, emocionava e servia de argumento para exigir do Estado recursos financeiros e construções de obras hídricas. Logo, esse era um importante instrumento regionalista para unificação do discurso dos grupos políticos dominantes do "Norte" na conquista de espaços no Estado republicano, comandado pelas oligarquias do "Sul”. Igualmente, as demais questões da região, como o atraso econômico, as migrações para o Sul e as manifestações messiânicas, eram justificadas pela influência do meio e da seca e camuflavam as formas dominantes de exploração que criaram a concentração das riquezas e do poder político, como o coronelismo, que gerou miséria e dependência nos sertanejos.

O discurso da indústria da seca compõe a imagem de um Nordeste abandonado, marginalizado, sofrido e pedinte, que necessita da intervenção do Estado para solucionar o problema da seca, ao tempo que ignora todas as áreas úmidas existentes na região e coloca alguns sujeitos políticos como porta-vozes desse espaço sofredor. Nesse sentido, "a seca, a terra rachada, a fome, embora atinjam só alguns espaços, alguns períodos e alguns grupos sociais da região, são generalizadas, tornam-se permanentes" (Albuquerque Jr., 1999, p. 199) e evidenciam uma visão equivocada dos sertões e caatingas do Nordeste do Brasil.

A lógica de combate à seca se consolidou, por um lado, na ideia de armazenar água: "a construção de grandes açudes, barragens, poços, cacimbas, entre outros, que foram concentrados em propriedades privadas, nos latifúndios dos detentores dos poderes políticos e econômicos da região" (Schroeder et al., 2014, p. 30). Por outro lado, medidas a curto prazo e assistencialistas foram implementadas, como a criação de frentes de emergência realizadas sob critérios políticos, na maioria das vezes, em terras de fazendeiros, bem como doações de cestas básicas e de carros-pipa de água que não resolviam o problema de acesso à água (Sudene, 1967).

Tal lógica é embasada "em soluções vindas de fora e aplicadas de forma impositiva e vertical". Além disso, envolve, muitas vezes, universidades e centros de pesquisas que propagam um conhecimento aprofundado, mas descontextualizado e construído sem a participação dos sujeitos locais (Conti et al., 2014, p. 134). O conhecimento científico levou à dominação e à negação de outros saberes.

Nesse sentido, percebe-se a lógica de combate à seca como uma forma de colonizar e dominar a natureza (colonialidade da natureza) e a indústria da seca como uma colonialidade do poder, do saber e do ser ao desconsiderar os sujeitos da região, seus aspectos culturais, seus conhecimentos e técnicas de como conviver com esse fenômeno ao invés de combatê-lo. O verdadeiro drama da dominação não é explicitado, visto que a diversidade do semiárido com suas caatingas, sertões e disponibilidades de 
água aí relacionadas é invisibilizada, desconsiderada . Tal aspecto foi destacado por Ab'Saber (2003), ao ressaltar que é pura falácia dizer que é necessário ensinar o nordestino a conviver com a seca.

\subsection{Colonialidades originadas do processo de modernização da agricultura}

A modernização da agricultura no Semiárido promoveu a colonização dos bens naturais e ocasionou invisibilidade, marginalização, expropriação de territórios e do modo de vida camponês da região, isto é, a colonialidade da natureza. Como afirma Walsh (2008), a colonialidade da natureza não se resume aos processos de dominação/exploração dos bens naturais, tendo em vista que os humanos são elementos integrantes dessa natureza. Nesse sentido, a colonialidade da natureza se refere também às formas coloniais de poder que afetam o mágico-espiritual-social, dimensão que sustenta os sistemas integrais da vida desde seus territórios.

Vandana Shiva $(1995 ; 2003)$ enfatiza que todas as sociedades camponesas não ocidentais organizavam seu modo de vida em torno da sustentabilidade e da reprodução da vida em toda sua riqueza e diversidade. Entretanto, a partir da colonização, muitas dessas sociedades foram dizimadas ou dominadas e aderiram à cultura de destruição dos bens naturais ${ }^{1}$ ou passaram a migrar para outras áreas.

Esse processo de transformações na forma de se relacionar com a natureza, especialmente no fazer agricultura, se intensificou com a Revolução Verde e a entrada dos pacotes tecnológicos nas atividades agrícolas. A Revolução Verde foi um processo que se deu a partir da busca por uma produção em larga escala com início na década de 1950 em vários países do mundo e entre os anos 1960 e 1970 no Brasil. Um ciclo de inovações tecnológicas adquiridas com os avanços do pós-guerra iniciou-se a partir de então, por meio de uma tecnologia de controle da natureza de base cientifico-industrial, sob o pretexto de acabar com a fome no mundo. (Pereira, 2012 p. 687).

No Semiárido, o período de 1960 a 1980, por exemplo, foi de rápida ocupação por capitalistas do Centro-Sul que, apoiados pelo Estado, desenvolveram uma moderna agricultura irrigada (Araújo, 2000) e contribuíram, historicamente, para a concentração de terras e a expulsão dos camponeses. Assim, configurou-se uma estrutura fragmentada: "Uma estrutura agrária marcada pelo dualismo: latifúndio/minifúndio; agricultura de exportação de um lado e uma agricultura camponesa de outro" (Silva, 2015, p. 53).

Desse modo, o processo de modernização agrícola não levou o sonhado "desenvolvimento" para os sujeitos do campo. O que se observa concretamente são as múltiplas facetas da colonialidade. Como menciona Vandana Shiva (2003), a violência contra a natureza, intrínseca ao modelo colonial-moderno-capitalista, se associa também à violência contra camponeses e camponesas que necessitam da natureza para obter o sustento de suas famílias.

Igualmente, a natureza é colonizada quando a ciência moderna a toma como objeto de conhecimento e destrói sua integridade, tanto no processo de percepção como no de manipulação. Ana Primavesi (1994) destaca que a natureza obedece a princípios

\footnotetext{
${ }^{1}$ Ver Oliveira \& Silva (2019).
} 
próprios, que estão imbuídos numa teia de relações e inter-relações. Assim, não existe fator isolado. E, por isso, o ser humano não pode simplesmente se afastar de suas leis, querendo dominar, modificar e explorar, sem considerar que faz parte desse conjunto.

A agricultura ancorada na ciência moderna e na lógica desenvolvimentista disseminou em diversas partes do mundo princípios que não são os da natureza como caminho para o "desenvolvimento" agrícola (Gliessman, 2002; Altieri, 2012). Tais princípios tornaram-se hegemônicos e levaram a diversas consequências.

Altieri (2012) cita como consequências concretas o fato de a agricultura moderna não considerar que um cultivo ou a falta dele pode interferir em outro; muitas vezes, esse tipo de agricultura estuda as propriedades físicas do solo separadamente das propriedades biológicas e da vida que mantém tais propriedades. Fazem parte dessas práticas equívocos como o processo de arar a terra com as mesmas técnicas e equipamentos norte-americanos, sem considerar que um país tropical como o Brasil apresenta condições distintas; e quando se supõe que a produção agrícola pode ser entendida objetivamente, sem levar em consideração os(as) camponeses(as) e sua maneira de pensar, os sistemas sociais e os agroecossistemas ao seu redor.

Essa abordagem colonial e reducionista da agricultura é inadequada, visto que só enxerga a biodiversidade como mercadoria e de forma fragmentada e atomizada para atender aos interesses comerciais, mas não para atender aos critérios ecológicos e sociais daqueles que são guardiões e guardiãs da biodiversidade (Shiva, 2003).
Ainda no âmbito da agricultura, vale mencionar a assistência técnica e extensão rural como um exemplo claro de colonialidade do saber, pois considera apenas determinadas formas de conhecimento construídas para os planos do capital e do desenvolvimento que subalternizam outros saberes e sensibilidades.

No Semiárido, quando se trata de assistência técnica, nota-se que as ações desenvolvidas junto aos camponeses e camponesas, nas últimas décadas, têm desvalorizado os saberes e tecnologias, considerando-os como obsoletos e improdutivos (Baptista \& Campos, 2013b). Os ideais da modernização agrícola foram apropriados e difundidos pelos profissionais de assistência técnica e extensão rural, ao adotarem uma visão tecnicista em que o extensionista é o sujeito e o camponês é o objeto de persuasão. Freire (1983) lembra que o próprio termo extensão não corresponde a uma troca de conhecimento, uma dialógica na qual quem ensina aprende e quem aprende ensina. O termo sugere a ideia de que o extensionista é aquele que leva o conhecimento, que estende algo a alguém. O autor entende que a assistência técnica é indispensável, mas só é válida se for além do treinamento técnico, buscando o diálogo com os(as) camponeses(as) para, de forma dialógica, conhecer e transformar a realidade. Nesse sentido, é fundamental uma assessoria técnica que entenda a sua atuação segundo a perspectiva da agroecologia ${ }^{2}$, reconhecendo as práticas de convivência.

Igualmente, não é possível falar de colonialidade da natureza sem mencionar o impacto disso sobre as mulheres. Afinal, mulher e terra foram vistas historicamente de forma análoga, controladas

${ }^{2}$ Ver Pereira (2016). 
e exploradas pelo colonizador masculino. De acordo com Quijano (2005), as relações entre os gêneros foram também ordenadas em torno da colonialidade, pois, em uma sociedade patriarcal, a mulher é subjugada ao homem.

Conforme Vandana Shiva (1995), a mulher foi excluída ou invisibilizada dos processos produtivos, políticos, econômicos e científicos ao longo da história. Desse modo, são as maiores vítimas do desenvolvimento e das colonialidades do poder, do saber, do ser e da natureza.

No que se refere ao Semiárido, são exemplos das relações de dominação, exploração ou invisibilidade das mulheres: a) invisibilidade do trabalho na produção agrícola, considerado muitas vezes como simples "ajuda"; b) desvalorização do trabalho doméstico; c) domínio sobre o corpo e subordinação sexual, pois muitas mulheres não têm autonomia sobre a vida reprodutiva, uma vez que os companheiros dificultam a laqueadura ou recusam o uso de outras formas contraceptivas; d) violência doméstica; e) exclusão de propostas das mulheres nos espaços políticos, como as associações locais (Fischer, 2004); f) as diversas formas de opressão machista que inferiorizam as mulheres.

No âmbito das atividades agrícolas, foco deste tópico, percebe-se que as camponesas do Semiárido desempenham um papel importante na segurança alimentar da família, pois são elas as responsáveis pelos quintais produtivos nos arredores da casa, hortas, plantas medicinais, armazenamento das sementes crioulas, valorização da água como um bem comum e diversas atividades que permitem a conservação dos bens naturais.
A mulher camponesa está integrada à natureza de forma complexa, ela vai além da simplificação imposta pela lógica colonial-moderno-capitalista. Como menciona Vandana Shiva (1995), a mulher do campo produz e reproduz a vida não só biologicamente, mas também com a sua função social de promover o sustento em interação com a natureza. Ela não só recolhe e consome os frutos da natureza, mas também faz produzir e crescer as coisas; sobretudo, há uma relação complexa a partir da interação entre mulher e natureza. Uma dimensão a ser ressaltada desta relação diz respeito à apropriação da natureza pela mulher que não constitui uma relação de dominação, mas de cooperação com a terra. $\mathrm{O}$ trabalho das mulheres é responsável por manter a ecodependência entre árvores, animais e cultivos na produção de alimentos e evidencia que a agricultura realizada em aprendizado com a natureza tem sido autorreprodutora e sustentável, porque os bens são renovados internamente (Shiva, 1995).

Ainda assim, em muitas situações, as mulheres têm sua participação nos espaços públicos invisibilizada e o companheiro se mantém como gerente dos recursos financeiros e chefe da família. Quando assumem a chefia da família, as mães solteiras, as "mulheres separadas" ou as "viúvas de marido vivo" transformam-se em um ser masculinizado, consideradas no discurso regionalista como mulher-macho.

Entretanto, apesar do contexto de colonialidades exercidas, as mulheres vivem em resistência para superar a crise ecológica e as amarras coloniais. Nesse sentido, Vandana Shiva propõe a perspectiva do princípio feminino ${ }^{3}$ como possibilidade de frear a contínua colonização da natureza e das demais

\footnotetext{
3 "Um projeto político, ecológico e feminista que legitima a vida e a diversidade e elimina a legitimidade do conhecimento e de práticas de uma cultura de morte que serve de base para a acumulação do capital" (Shiva, 1995, p. 44).
} 
formas de colonialidades e privações de que padecem não somente as mulheres, mas a natureza e as culturas locais. As mulheres representam também um modo de produção com base em princípios de solidariedade, libertação da natureza, da mulher e dos homens que, dominando a natureza e a mulher, tem sacrificado a própria humanidade (Shiva, 1995).

\subsection{Colonialidades originadas dos processos educativos}

Quando se analisam os processos educativos nas áreas rurais, percebe-se que a educação é inicialmente negada aos camponeses, o que coloca em evidência de imediato uma colonialidade do poder, na qual são escolhidos a priori os sujeitos que têm direito ou não à educação.

De acordo com Ribeiro (2013), somente a partir de 1930 o Estado começa a intervir mais efetivamente sobre a educação no contexto rural. No entanto, quando finalmente é sinalizada aos camponeses, a educação se dá na lógica colonial-moderno-capitalista. Uma educação pensada de cima para baixo, em que os(as) camponeses(as) são sujeitados à educação para se adaptarem ao processo de subordinação do modo de produção capitalista. Uma concepção que considera o modo de vida camponês atrasado e marginalizado em relação ao desenvolvimento capitalista, logo, carente de ser integrado ao progresso resultante desse desenvolvimento. Porém, a construção, a aplicação e a avaliação desse projeto de educação voltado para o campo não tiveram a participação das populações rurais.

Assim, a educação é apresentada de forma assistencialista, tecnicista e como mola propulsora do desenvolvimento, portanto, necessária ao processo de modernização agrícola. A educação funcionou para formar força de trabalho disciplinada, para estimular os(as) camponeses(as) a consumir os produtos das empresas agrícolas e, ao mesmo tempo, para eliminar os saberes acumulados pela experiência camponesa (Ribeiro, 2013).

Além disso, vale destacar que o ensino era ofertado sob os moldes da educação urbana, seguindo os mesmos parâmetros e referências. Nesse sentido, a educação, o ensino e a escola no campo tornaram-se espaços de negação do povo e da cultura camponesa, "criando outros modos de silenciamento através do conhecimento científico de caráter instrumental" (Torres \& Lemos, 2012, p. 8). Assim, as colonialidades do poder e do saber evidenciam-se na imposição de pacotes educacionais descontextualizados da realidade dos sujeitos do campo, atendendo a uma lógica de sociedade que não é a lógica camponesa.

Essa realidade apresentada não é diferente no contexto do Semiárido brasileiro. Baptista e Campos (2013b) explicam que "[...] as elites brasileiras sempre afirmaram que o Semiárido não possui nem produz conhecimentos, e que seu povo é atrasado na educação" (p. 85). É assim que se justificaria a tese de que para "salvar" o Semiárido seria necessário trazer conhecimentos de fora. De acordo com os autores, a educação é negada ao povo do semiárido, especialmente aos camponeses, de três maneiras:

Primeiro, porque a população mais pobre do semiárido ficou sem acesso às possibilidades de "educar-se" nos moldes oficiais determinados pelo país e suas autoridades, através do acesso à escola, universidades e livros, pois assim se tornava mais vulnerável e manipulável; depois, porque eram coibidas, pela força, quaisquer tentativas existentes de organizar-se 
e produzir outro conhecimento; e, finalmente, porque seus conhecimentos e processos educacionais eram catalogados e tidos como folclore, magias, superstições, diabólicos, ridicularizados e, por isso, deviam ser condenados e evitados (Baptista \& Campos, 2013b, p. 85).

Essa colonialidade do poder, do saber e do ser resultou, no Semiárido, numa enorme massa de analfabetos, produziu escolas que estimularam o êxodo rural e geraram nos sujeitos do campo uma sensação de inferioridade não só pela sua condição econômica, mas também em relação aos seus saberes deslegitimados. Também decorre disso o fato de ainda hoje muitos(as) camponeses(as) incentivarem os filhos a sair dessa condição por meio do "estudo na cidade".

No que se refere às escolas, Baptista e Campos (2013b) afirmam que as perspectivas, os valores, a música, os costumes, as danças, as comidas, as lutas do povo do Semiárido são dimensões ausentes nos livros didáticos e nos debates da escola. Assim, a escola educa os filhos dos camponeses para desconhecerem e terem vergonha de sua própria cultura e modo de ser, para migrarem e renunciarem a si mesmos e a sua região. Boaventura de Sousa Santos denomina esse processo como epistemicídio (Santos, 2018).

Vale salientar que os processos de educação não formal também exerciam a colonialidade do saber. Instituições como centros comunitários, paróquias e sindicatos rurais, tomados como parceiros do Estado, recebiam os pacotes educacionais prontos para serem colocados em prática, de modo que não podiam modificar seus objetivos, conteúdos e metodologias (Ribeiro, 2013). Do mesmo modo, muitas organizações que buscavam metodologias participativas também acabavam exercendo certa colonialidade do poder em não escutar os camponeses e levar "pacotes alternativos" prontos e descontextualizados da realidade dos camponeses.

Quando se analisa a escola atualmente, observa-se como as colonialidades se transformam. Ribeiro (2013) menciona que os objetivos iniciais de formar os camponeses para participarem do processo de modernização agrícola foram atingidos. Deste modo, outros objetivos são estabelecidos, como o fechamento das escolas do campo e os processos de nucleação das escolas rurais. Assim, as escolas continuam transmitindo a realidade urbana para os estudantes e muitas vezes desestruturando as famílias, seu modo de vida e sua cultura, uma vez que as famílias se veem obrigadas a migrar para a cidade para manter os filhos estudando.

No entanto, vale destacar que, em meio aos processos de colonialidades no âmbito da educação, também vão existir, simultaneamente, os processos de resistência, como o da educação popular freiriana, a partir dos anos 1960 .

No tocante aos camponeses, a resistência não consistia em negar a educação em si, pelo contrário, a educação foi uma das primeiras demandas dos movimentos sociais camponeses. No entanto, esses movimentos contrapõem-se à educação rural (matriz colonial de poder) e reivindicam uma educação do campo, associada a um projeto popular para o Brasil - uma educação popular (Ribeiro, 2013).

Diante do exposto, compreende-se que as diversas colonialidades impostas ao Semiárido operam para produzir o que Boaventura de Sousa Santos (2018) vai chamar de ausências, isto é, produzir certos grupos de pessoas e formas de vida social como não existentes, invisíveis, ignorantes, improdutivos ou radicalmente inferiores. 
No entanto, por trás das colonialidades estão os processos de resistência, que coexistem numa relação complexa, isto é, complementar, concorrente e antagônica, com as diversas colonialidades, o que Walsh (2008) vai chamar de decolonialidade ou o que Boaventura de Sousa Santos (2018) denomina de emergências ${ }^{4}$. Nas últimas três décadas, esses processos têm caminhado para além das resistências no semiárido. O que se observa é um processo de articulação para descolonizar os discursos e as práticas acerca do Semiárido e fazer emergir um novo paradigma - o paradigma da convivência com o Semiárido.

\section{Racionalidade camponesa e o paradigma da convivência com o Semiárido: um caminhar para além do desenvolvimento?}

[...] defender um modo de vida relativamente autossuficiente e resistir a ser espoliado das condições materiais que o tornam possível já representa em si mesmo uma alternativa ao desenvolvimento (Lang, 2016. p. 42).

A etimologia da palavra desenvolvimento expressa algo como "sem movimento para reverter a ação" ou "sem envolvimento". DES (prefixo de negação) IN (movimento para dentro) VOLVER (reverter) MENTO (sufixo de ação). Mas, quando consultada em um dicionário, a palavra desenvolvimento significa "o ato ou efeito de desenvolver", "fazer progredir" ou "crescimento" (Santos et al., 2012). Em princípio, é um processo natural, tendo em vista que as plantas, os animais e os seres humanos se desenvolvem a partir de uma semente, um ovo, um embrião, até alcançar a maturidade (Lang, 2016). Desse ponto de vista, é natural que os seres humanos busquem se desenvolver, busquem a satisfação das suas necessidades da melhor maneira possível (Acosta, 2016).

Entretanto, Lang (2016) e Acosta (2016) enfatizam que esse processo natural serviu de inspiração para o binômio "desenvolvimento" e "subdesenvolvimento", proposto em 1949 no discurso de posse do presidente dos Estados Unidos, Harry Truman. $\mathrm{Na}$ ocasião, o presidente dividia o mundo em áreas desenvolvidas e áreas subdesenvolvidas, entendidas a partir de então como descrição do estado de uma economia ou sociedade.

A ideia de desenvolvimento referenciada nos países industrializados relegou aos demais países a condição de subdesenvolvimento. Um discurso universal, progressista e linear em que o foco principal seria o desenvolvimento econômico baseado no sistema colonial-moderno-capitalista, isto é, baseado no progresso técnico-científico e na exploração dos bens naturais que, consequentemente, levariam à melhoria na qualidade de vida das pessoas, avanços sociais, culturais e políticos (Lang, 2016; Gudynas, 2017).

No entanto, até hoje, a chamada "cooperação ao desenvolvimento" transfere muito mais recursos do Sul para o Norte do que vice-versa (Lang, 2016). Os países do Sul global têm vivenciado a ilusão de sair da pobreza, mas os resultados concretos do desenvolvimento têm servido para que as nações

\footnotetext{
${ }^{4} \mathrm{O}$ autor entende por emergências as capacidades e as possibilidades concretas de um futuro que se inscreve no presente. Um futuro concreto, embora incerto e em perigo. São realidades embrionárias, como movimentos incipientes, tendências que guiam para novas constelações de sentido referentes tanto à compreensão como à transformação do mundo (Santos, 2018).
} 
ricas se tornem mais ricas, enquanto os países do Sul global continuam lidando com seus problemas de pobreza. (Gudynas, 2017).

Essa situação evidencia as diversas colonialidades impostas nos países do Sul global, pois o modo de vida ocidental só é possível em decorrência das relações coloniais. Acosta (2016) afirma que não se pode mais sustentar o discurso do desenvolvimento que, com suas raízes coloniais, justifica visões excludentes.

A esse respeito, Lang (2016) afirma que:

Os modos de organizar a sociedade e a economia, os modos de conceber o mundo e de estar nele, os conhecimentos e saberes de grande parte da população mundial foram desqualificados como pobres, atrasados, insuficientes, por uma única razão: existiam por fora do sistema de produção e dos mercados capitalistas. Essa é a meta do "desenvolvimento": incluir territórios não totalmente permeados pelas lógicas e práticas capitalistas aos circuitos de acumulação de capital, transformar populações em consumidores, camponeses de subsistência em assalariados ou informais, bens naturais em commodities, propriedade coletiva em privada e vendável. Com um só objetivo: aumentar os fluxos de dinheiro e, assim, o "crescimento econômico", paradigma irmão do “desenvolvimento" (Lang, 2016, p. 31).

Ainda de acordo com a autora, isso implica a destruição de culturas não ocidentais e a destruição de outros modos de vida, para atender à lógica colonial-moderno-capitalista. Conforme já apresentado no tópico anterior, o projeto de desenvolvimento voltado para o Semiárido brasileiro está baseado em tal lógica, portanto, exerce várias colonialidades ao não considerar as características da região, ao mercantilizar e artificializar a natureza e partir do pressuposto de ser esta uma região problema, onde não chove, de natureza morta, lugar do atraso e do subdesenvolvimento.

Assim, se prega o discurso de acabar com o limite da semiaridez para desenvolver a região e transformá-la em lugar de prosperidade, desconsiderando que esse limite está circunscrito ao domínio das caatingas brasileiras e dos sertanejos, conforme coloca (Ab'Saber, 2003). No entanto, a modernização agrícola e a construção de grandes obras hídricas, por exemplo, não aumentaram a disponibilidade de água para os camponeses nem melhoraram suas técnicas produtivas, ao contrário, ampliaram processos de concentração de terra e dependência econômica e política (Araújo, 2000).

Nesse sentido, reforça-se que tal modelo de desenvolvimento desconsidera os saberes, o modo de vida e as cosmologias daqueles que fazem agricultura há mais de dez mil anos - camponeses e camponesas. Sabe-se que a racionalidade camponesa está pautada em outras formas de conhecimento que não necessariamente o conhecimento científico racional e não segue a lógica do capital de transformar tudo em mercadoria.

Assim, como aborda Lang (2016), diferentemente do "desenvolvimento" que segue um caminho traçado, considerado universalmente válido e baseado no conhecimento especializado e na ciência moderna, existem outras alternativas e essas são multiformes, têm sujeitos diversos, ocorrem em muitos âmbitos e em sentidos temporais variados. Seus horizontes são os bons viveres, contextualizados, baseados na aprendizagem coletiva e na aprendizagem com a Natureza.

Arturo Escobar (1995), analisando outras realidades da América Latina, aponta duas direções complementares que são alternativas ao desenvolvimento e às diversas formas de colonialidades que 
são impostas: a resistência local de grupos de base às formas dominantes de intervenção e a desconstrução, desnaturalização e desuniversalização da modernidade e do desenvolvimento.

Nesse sentido, pode-se dizer que tais direções podem ser pensadas no contexto em estudo ao se falar em Semiárido, ao invés de Nordeste. O termo Semiárido é menos carregado de significados pejorativos e supõe a emergência de um novo paradigma - o paradigma da convivência com o Semiárido. Um paradigma que desbanaliza, descoloniza e desconstrói a visão de "região problema dominada pela seca", "região do atraso", bem como a visão reducionista fundamentada na lógica do desenvolvimento e do domínio da natureza (lógica colonial-moderno-capitalista).

Disso decorre a importância de se pensar em Semiárido ao invés de Nordeste e a necessidade de que a história desse Nordeste-Outro seja recontada pelos sujeitos que o compõem, a fim de descolonizar a imagem inventada e imposta para a região - uma sociologia das ausências, como menciona Santos (2018). Afinal, como afirma Chimamanda Adichie, é um perigo ouvir apenas um lado da história, porque é impossível falar de uma única história sem falar sobre poder (TED, 2009).

Conforme já discutido, o Nordeste é inventado e contado tomando-se por base diversas colonialidades que criam estereótipos para a região. Obviamente, muito do que se apresenta em relação ao Nordeste é fato. A seca existe, a pobreza existe, o fanatismo religioso existe, mas esses fenômenos e problemas são apresentados de forma incompleta e negligenciam uma infinidade de conhecimentos existentes na região que, se levados em consideração, poderiam resultar em políticas públicas adequadas para o Semiárido. O Semiárido "não é apenas clima, vegetação, solo, sol ou água. É povo, música, festa, arte, religião, política, história. É processo social. Não se pode compreendê-lo de um ângulo só" (Malvezzi, 2007, p. 9).

Uma história contada de um ângulo só superficializa uma experiência (TED, 2009) e uma realidade. Exemplo disso é apontado por Malvezzi (2007), quando menciona o gosto da mídia em publicar imagens do chão seco e esturricado de lagoas e barreiros do Semiárido para mostrar uma região seca e inviável. Um sertanejo vai dizer que tal imagem não representa a seca, pelo contrário, vai mostrar "que já choveu, que ali havia água, mas que ela evaporou, deixando a aparência de lama ressecada no chão" (Malvezzi, 2007, p. 78). Nesse caso, a mesma imagem mostra duas histórias: uma apresenta uma suposta seca e outra evidencia o problema da evaporação e não da seca.

A convivência com o Semiárido diz respeito a uma racionalidade vivenciada historicamente pelos diversos sujeitos sertanejos, na qual se reconhecem as fragilidades da região, bem como sua originalidade, suas potencialidades, sua complexidade e diversidade étnica, racial, cultural e política (Silva, 2006).

As reflexões sobre um paradigma emergente da convivência ocorrem a partir da constatação das anomalias da lógica colonial-moderno-capitalista e buscam extrapolar os limites dessa lógica. Mas, como enfatizam as diversas lideranças da Articulação Semiárido Brasileiro (ASA), a desconstrução e a reconstrução não emergem de gabinetes e ou de mentes iluminadas, mas da vida concreta dos camponeses e camponesas, dos movimentos sociais e de alguns institutos de pesquisa que estão inseridos na região. Por isso, a convivência com o semiárido tem como estratégia básica reconhecer a 
capacidade de produção e de conhecimento desses sujeitos, basear-se em suas aprendizagens, não impor tecnologias e, simultaneamente, reconhecer o valor dos estudos e trabalhos científicos sobre o Semiárido e sua viabilidade (ASA, 2010).

O paradigma da convivência parte do princípio-chave de que as populações do semiárido não são simplesmente receptoras de conhecimentos e técnicas, pelo contrário, possuem e são capazes de gerar os conhecimentos necessários ao seu modo de vida, "sem negar, com isso, a necessária inter-relação com outras populações, conhecimentos e tecnologias" (Baptista \& Campos, 2013c, p. 64).

Boaventura de Sousa Santos (1981) menciona que o campesinato é complexo e multifacetado, logo, julgá-lo pelos critérios da ciência moderna, do conhecimento disciplinar e da racionalidade capitalista é uma postura reducionista e mutiladora. Pela sua complexidade, o campesinato não pode ser igualado ou comparado a uma empresa agrícola, por exemplo. O campesinato tem formas e motivações próprias, que estão intimamente ligadas ao seu processo de trabalho e, portanto, não podem aderir a lógicas impostas que desconsiderem as diversas dimensões do campesinato.

Como mencionam Woortmann \& Woortmann (1997), o trabalho é fundante na vida dos camponeses e permeado pelo saber técnico e pelo saber simbólico, que se complementam. Os camponeses dominam o saber fazer e organizam seus agroecossistemas com base em vários fatores, como as condições do solo, a disponibilidade de água, as necessidades alimentares da família, as plantas que são companheiras ou alelopáticas, dentre outros. Já os saberes simbólicos garantem o domínio das crenças religiosas que vão além das relações produtivas. Os elementos da natureza, como a lua, atuam profundamente sobre a tomada de decisões, no planejamento e na execução das atividades agrícolas. Os(as) camponeses(as) lançam mão de seus saberes sobre os elementos simbólicos, abstratos e sobrenaturais para intervir em suas atividades cotidianas, demonstrando que suas percepções representam também suas conexões com a natureza circundante.

Nesse sentido, observa-se que não existe distinção entre o espaço produtivo e o social, entre os saberes técnicos e simbólicos. Os(as) camponeses(as) encontram formas criativas para viver em aprendizado e em convivência numa estreita relação com o seu trabalho e com a natureza.

Assim, abaixo estão listadas algumas das diversas estratégias de resistência e de convivência que garantem a esses sujeitos a permanência no campo e a utopia de caminhar para além do desenvolvimento.

- O povo do Semiárido resiste pela organização e mobilização social. O paradigma da convivência é a afirmação de um projeto político que reivindica o acesso à terra e à água, e o direito de jovens, mulheres e comunidades tradicionais. Um Semiárido de vida e de possibilidades que não considera o camponês e a camponesa como coitados, mas sujeitos capazes de contar sua história e fazer seu destino, desde outra visão de mundo. No que se refere à mobilização das mulheres, percebe-se cada vez mais a participação ativa nas associações locais, nos conselhos municipais, nos sindicatos e nos movimentos mais amplos, como a participação na Marcha das Margaridas. Cabe enfatizar a importância desses espaços como ferramentas para que as mulheres 
falem, reflitam e participem ativamente da construção do paradigma da convivência. E nesse sentido a auto-organização funciona como um espaço de fortalecimento que torna as mulheres protagonistas na luta e nas suas vidas. Igualmente, a organização social evidencia o trabalho da mulher como um trabalho socialmente útil, que precisa ser valorizado e respeitado.

- O povo do Semiárido resiste através da educação popular em suas múltiplas práticas sociopedagógicas (Educação do Campo, Educação contextualizada, Educação não formal). Não se trata de uma "perspectiva messiânica de transformar o mundo" nem de pensar como "educação única e verdadeira", mas como uma alternativa contraposta às colonialidades impostas e um instrumento a serviço dos camponeses (Ribeiro, 2013). A educação popular busca "educar para a liberdade, o respeito, a autoestima, a solidariedade, o respeito à natureza" (Baptista \& Campos, 2013b, p. 89). Uma educação sempre compromissada com o contexto e que não se reduz à escolarização ou ao conhecimento científico. São exemplos concretos no Semiárido: a assessoria técnica agroecológica promovida por diversas organizações; os cursos superiores em Educação do Campo com a metodologia da pedagogia da alternância; os processos de formação promovidos pelos Núcleos de Agroecologia das instituições de ensino e pesquisa; Escolas Família Agrícola e o importante papel desenvolvido pela Rede de Educação do Semiárido Brasileiro (RESAB).
- O povo do Semiárido resiste pela revolução silenciosa da comunicação popular. A comunicação é uma ferramenta estratégica para entender o Semiárido para além do acesso à terra e à água, mas por outro projeto de sociedade. Roberto Malvezzi (2007) afirma que o surgimento das rádios comunitárias, o avanço dos movimentos populares nas bases e a expansão da internet contribuíram para reduzir o poder dos grandes meios de comunicação, principalmente a televisão. A comunicação popular é uma estratégia de luta que desperta a consciência dos sujeitos para romper com as colonialidades da comunicação hegemônica. Além disso, permite que o Semiárido seja contado por sua gente. São exemplos concretos dessa revolução no Semiárido: os boletins das organizações como $O$ candeeiro e Dois dedos de prosa; as cartilhas; os sites; o cordel, linguagem de domínio do povo semiárido; a fotografia como ferramenta de anúncio e denúncia; a música; bem como as rádios, que ainda são muito escutadas pelas comunidades rurais.

- Os camponeses e camponesas do Semiárido resistem há tempos ao projeto de desenvolvimento ao construir alternativas ao sistema colonial-moderno-capitalista com base em economias solidárias e princípios da sociabilidade rural camponesa, como as trocas e doação de produtos, mutirões nas atividades produtivas, fundos rotativos solidários, bancos de sementes crioulas, dentre outros.

- As tecnologias sociais partem do conhecimento e das práticas locais para viabilizar os agroecossistemas camponeses. Tais tecnologias tendem a incrementar a biodiversidade 
local e a conservação da natureza. Muitas tecnologias de captação e manejo da água de chuva, como as cisternas de placas de 16 mil litros, cisterna-calçadão, cisterna-enxurrada, barragem subterrânea, barreiros trincheira, barraginha, tanque de pedra, dentre tantas outras, permitem que camponeses e camponesas permaneçam no campo em resistência e em construção de outro paradigma. Além disso, as tecnologias sociais enfraquecem a colonialidade do poder local sobre a população, visto que não se aceita mais, por exemplo, trocar voto por água.

- Os camponeses mostram resistência pela diversificação e pelo beneficiamento da produção. Os quintais produzem durante ano inteiro uma vasta variedade de plantas frutíferas, hortaliças e plantas medicinais, além da área de mata e da criação de animais, o que garante a segurança alimentar da família e a autonomia relativa em relação aos impérios alimentares.

- Alternativas de complementação da renda familiar com a pluriatividade. Em Silva (2015, p. 125), identificou-se que a decisão de desenvolver atividades não agrícolas combinadas com atividades agrícolas no Semiárido está associada não só à pouca disponibilidade de terra, mas também às estiagens na região. A pluriatividade passa a ter um papel importante na reprodução camponesa e na sustentabilidade de sua base produtiva, pois "na medida em que as famílias passam a combinar a agricultura com atividades não agrícolas, tendem a atenuar a pressão sobre os bens naturais dos agroecossistemas, em sua maioria minifúndios". Além disso, “ao promoverem a ocupação da força de trabalho e a geração de renda, as atividades não agrícolas colaboram para a permanência das famílias no campo".

- Os camponeses e camponesas resistem por meio do seu saber-fazer. Os fenômenos da cultura e da natureza estão intimamente integrados e devem ser observados em suas íntimas relações. A diversidade cultural, muitas vezes, corresponde à diversidade biológica, ambas em processo histórico de destruição, a partir do avanço do sistema colonial-moderno-capitalista em todas as esferas e da necessidade de domínio da natureza (Whitaker \& Bezzon, 2006). Logo, o saber-fazer camponês é uma ferramenta essencial no Semiárido, especialmente porque a lógica e as temporalidades camponesas são muito distintas da lógica do capital. Um bom exemplo, citado por Woortmann \& Woortmann (1999), que contraria a perspectiva da lógica dominante é o fenômeno da velhice. O velho camponês não é um inativo, mas um detentor de saber e autoridade na família e na comunidade que exerce o trabalho desde outra dimensão. Geralmente são os mais velhos que, com base na observação e na experimentação direta com a natureza ao longo dos anos, repassam os aprendizados para o núcleo familiar. São exemplos desses conhecimentos no Semiárido: observações de que algumas datas, como 19 de março (São José), 25 de dezembro (Natal), $1^{\circ}$ de janeiro (Ano Novo), 13 de dezembro (Santa Luzia) e 06 de janeiro (Reis) são dias de grandes possibilidades de chuvas e de que a falta de chuva nessas datas é um péssimo 
sinal para a produção; a antecipação de que uma boa safra de umburana de cheiro é sinal de que o ano seguinte terá um bom inverno; a identificação de qual lado do umbuzeiro produz mais frutos, pois o lado com maior carga de frutos [maior significa que as] receberá melhores chuvas; a utilização de indicadores de clima baseados na fenologia (início da floração) das plantas da caatinga para saber onde, quando e o que plantar; dentre outros. Os camponeses e camponesas compartilham desde receitas de remédios com plantas medicinais a práticas de conservação das sementes e armazenamento de forragens para os animais, o que demonstra grande conhecimento da vida em convivência com a natureza e com a Caatinga.

- A festa é um dos fatores imprescindíveis de agregação na cultura camponesa do Semiárido. Para Roberto Malvezzi (2007), a festa explica muito da permanência do povo sertanejo no meio rural e de sua resistência em se manter no campo, apesar de qualquer adversidade. A capacidade de passar uma semana em carnaval, as festas de casamento que duram dois ou três dias, a festa do milho, a festa do caju, a festa da pitomba, os forrós em qualquer circunstância tornam o povo nordestino quase incompreensível para os olhos "produtivos" da lógica colonialmoderno-capitalista. Muitas vezes, isso dá margem ao preconceito e aos estereótipos. A ideia da preguiça, da irresponsabilidade, oculta em piadas e insinuações bastante comuns, decorre da incompreensão dessa cultura e da lógica de se viver sob a ótica de outro paradigma.

\section{- A resistência também acontece dentro} da própria rede de poder. Hoje ainda se faz ciência aos moldes do colonizador, a diferença é o que pode ser feito com esse conhecimento até a transição para uma nova ciência. Embora a conjuntura política brasileira atual não favoreça a educação, muitos camponeses chegaram à universidade $\mathrm{e}$ fazem resistência a esse modelo externo à natureza. Muitos cientistas de origem não camponesa também denunciam a irracionalidade da ciência moderna e do modelo de desenvolvimento vigente, tomando por base a construção de conhecimento de forma crítica e que considere o diálogo de saberes.

\section{Considerações finais}

Como exposto neste artigo, o Semiárido brasileiro é uma região diversa, multifacetada e com diversas potencialidades, circunscrita no domínio das caatingas e sertões. Mas, desde o período colonial, sofre devastações da natureza, empobrecimento da população e perdas da diversidade biológica e cultural, em decorrência das relações coloniais de poder implantadas na região. Conforme exposto, acabou a colonização, mas permaneceram em seu lugar diversas colonialidades.

Entretanto, os processos de resistência coexistem numa relação complexa com as colonialidades. No contexto dessa decolonialidade, se apresenta o paradigma da convivência com o Semiárido. Um paradigma que procura ir além desse desenvolvimento que segue um caminho traçado, universalmente válido, baseado na lógica colonial-moderno-capitalista. Um paradigma que busca descolonizar e 
transgredir a lógica vigente desde as cosmologias/ visões de mundo dos sujeitos da região, ou seja, busca valorizar os conhecimentos, as práticas e os saberes que estejam situados e contextualizados na realidade semiárida, sem necessariamente excluir outros saberes.

\section{Referências}

Ab'Saber, A. N. Os domínios de natureza no Brasil: potencialidades paisagísticas. São Paulo: Ateliê Editorial, 2003.

Acosta, A. O bem viver: uma oportunidade para imaginar outros mundos. São Paulo: Autonomia Literária, Elefante, 2016.

Albuquerque Jr., D. M. D. A invenção do Nordeste e outras artes. São Paulo: Cortez, 1999.

Altieri, M. Agroecologia: bases científicas para uma agricultura sustentável. São Paulo: Expressão Popular, 2012.

Andrade, M. C. D. O Nordeste e a Nova República. Recife: Asa, 1987.

Andrade, M. C. D. Nordeste: alternativas da agricultura. Campinas: Papirus, 1988.

Andrade, M. C. D. A questão do território no Brasil. 2. ed. São Paulo: Hucitec, 2004.

Araújo, T. B. D. Ensaios sobre o desenvolvimento brasileiro: heranças e urgências. Rio de Janeiro: Revan/Fase, 2000.

ASA - Articulação Semiárido Brasileiro. Uma caminhada de sustentabilidade e de convivência com o Semiárido. Recife: ASA, 2010.

Baptista, N. D. Q.; Campos, C. H. A convivência com o Semiárido e suas potencialidades. In: Conti, I. L.; Schroeder, E. O. (Orgs.). Convivência com o Semiárido Brasileiro: autonomia e protagonismo social. Brasília: IABS, p. 5158, 2013a.

Baptista, N. D. Q.; Campos, C. H. Educação Contextualizada para a Convivência com o Semiárido. In: Conti, I. L.;
Sem dúvida, um grande desafio é a disputa política do espaço rural semiárido como território de produção e reprodução da vida em todos os seus aspectos e não como espaço de mercantilização da vida em nome de um suposto desenvolvimento que é colonial, moderno e capitalista.

Schroeder, E. O. (Orgs.). Convivência com o Semiárido Brasileiro: autonomia e protagonismo social. Brasília: IABS, 2013b. p. 83-96.

Baptista, N. D. Q.; Campos, C. H. Possibilidades de construção de um modelo sustentável de desenvolvimento. In: Conti, I. L.; Schroeder, E. O. (Orgs.). Convivência com o Semiárido Brasileiro: autonomia e protagonismo social. Brasília: IABS, 2013c. p. 59-72.

Castro-Gómez, S. Decolonizar la universidad: La hybris del punto cero y el diálogo de saberes. In: Castro-Gómez, S.; Grosfoguel, R. (Eds.) El giro decolonial: reflexiones para una diversidad epistémica más allá del capitalismo global. Bogotá: Siglo del Hombre Editores; Universidad Central, Instituto de Estudios Sociales Contemporáneos y Pontificia Universidad Javeriana, Instituto Pensar, 2007. p. 79-91.

Chaloult, Y. Estado, acumulação e colonialismo interno: contradições Nordeste/Sudeste, 1960-1977. Petrópolis: Vozes, 1978.

Conti, I. L.; Schroeder, E. O.; Medaglia, V. R. Um processo de formação sob o olhar de seus protagonistas In: Conti, I. L.; Schroeder, E. O.; Medaglia, V. R. Construindo saberes, cisternas e cidadania: formação para a convivência com o semiárido brasileiro. Brasília: IABS, 2014. p. 133-161.

Dantas, B. G.; Sampaio, J. A.; Carvalho, M. A. G. Os povos indígenas do Nordeste Brasileiro: um esboço histórico. In: Cunha, M. C. (Org.). História dos índios do Brasil. São Paulo: Companhia das Letras, 1992. p. 431-456.

Dantas, I. Coronelismo e dominação. Aracaju: UFS, 1987. 
Escobar, A. Encoutering Development: The Making and Unmaking of the Third World. Princeton: Princeton University Press, 1995.

Escobar, A. Sentipensar con la tierra: nuevas lecturas sobre desarrollo, território y diferencia. Medellín: UNAULA, 2014.

Etchevarne, C. A ocupação humana do Nordeste brasileiro antes da ocupação portuguesa. Revista USP, 44, 112-141, dez. 1999/fev. 2000. Disponível em: http://www.revistas.usp.br/revusp/article/view/30097/31982

Fischer, I. R. O protagonismo feminino no contexto da dominação: um estudo no acampamento do Engenho Prado. Recife, Tese (Doutorado em Serviço Social) - UFPE, 2004.

Freire, P. Extensão ou comunicação. 7. ed. Rio de Janeiro: Paz e Terra, 1983.

Gliessman, S. R. Agroecologia: procesos ecológicos en agricultura sostenible. Turrialba: Catie, 2002.

González-Casanova, P. Colonialismo interno (uma redefinição). In: Boron, A. A.; Amadeo, J.; Gonzalez, S. A teoria marxista hoje: problemas e perspectivas. Buenos Aires: Clacso, 2007. p. 431-458.

Gudynas, E. Posdesarrollo como herramienta para el análisis crítico del desarrollo. Estudios Críticos sobre el Desarrollo, 7(12), 193-210, 2017.

Guidon, N.; Delibrias, G. Carbon - 14 dates point to man in the Americas 32.000 years ago. Nature, 321, 769-771, 1986.

Guidon, N.; Parenti, F.; da Luz, M. de F.; Guérin, C.; Faure, M. Le plus anciens peuplement de l'Amérique: le Paléolithique du Nordeste brésilien. Bulletin de la Société Préhistorique Française, 91, 246-250, 1994.

Lander, E. A colonialidade do saber: eurocentrismo e ciências sociais. Ciudad Autónoma de Buenos Aires: Clacso, 2005.

Lang, M. Introdução: alternativas ao desenvolvimento. In: Dilger, G.; Lang, M.; Pereira Filho, J. (Orgs.). Descolonizar o imaginário: debates sobre pós-extrativismo e alternativas ao desenvolvimento. São Paulo: Fundação Rosa Luxemburgo, 2016. p. 24-45.
Leal, V. N. Coronelismo, enxada e voto: o município e o regime representativo no Brasil. 7. ed. São Paulo: Companhia das Letras, 2012.

Maldonado-Torres, N. La descolonización y el giro des-colonial. Comentario Internacional, 7, 65-78. 2007. Disponível em: https://revistas.uasb.edu.ec/index-.php/comentario/ article/view-/130

Malvezzi, R. Semiárido: uma visão holística. Brasília: Confea, 2007.

Mignolo, W. Colonialidade: o lado mais escuro da modernidade. Revista Brasileira de Ciências Sociais, 32(94), 1-18, 2017.

Oliveira, F. H.; Silva, V. R. Uso de agrotóxico ou controle agroecológico de pragas e doenças da agricultura: uma reflexão a partir do município de Alvorada do Gurguéia-PI. Brazilian Journal of Agroecology and Sustainability, 1, 1-20, 2019. Disponível em: http://www.journals.ufrpe.br/ index.php/BJAS/article/view/2925

Pereira, M. C. B. Revolução Verde. In: Caldart, R.; Pereira, I. B.; Alentejano, P.; Frigotto, G. (Orgs.). Dicionário da Educação do Campo. São Paulo: Expressão Popular, 2012. p. 687-691.

Pereira, M. C. B. Agroecologia na formação universitária: da ecologia à agroecologia e do ecossistema ao agroecossistema. Cadernos de Agroecologia, 11(1), 1-14, 2016. Disponível em: http://revistas.abaagroecologia.org. br/index.php/cad/article/view/20-881

Porto-Gonçalves, C. W. Apresentação. In: Lander, E. A colonialidade do saber: eurocentrismo e ciências sociais. Ciudad Autónoma de Buenos Aires: Clacso, 2005. p. 3-5.

Primavesi, A. Manejo ecológico de pragas e doenças: técnicas alternativas para a produção agropecuária e defesa do meio ambiente. São Paulo: Nobel, 1994.

Quijano, A. Colonialidad y modernidad-racionalidad. In: Bonillo, H. Los Conquistados. Bogotá: Tercer Mundo, Flacso, 1992. p. 437-449.

Quijano, A. Colonialidade do Poder, Eurocentrismo e América Latina. In: Lander, E. A colonialidade do saber: eurocentrismo e ciências sociais. Ciudad Autónoma de Buenos Aires: Clacso, 2005. p. 107-130. 
Quijano, A. Colonialidad del poder y clasificación social. In: Castro-Gómez, S.; Grosfoguel, R. (Eds.). El giro decolonial: reflexiones para una diversidad epistémica más allá del capitalismo global. Bogotá: Siglo del Hombre Editores; Universidad Central, Instituto de Estudios Sociales Contemporáneos y Pontificia Universidad Javeriana, Instituto Pensar, 2007. p. 93-126.

Ribeiro, M. Movimento camponês, trabalho e educação: liberdade, autonomia, emancipação como princípios/fins da formação humana. 2. ed. São Paulo: Expressão Popular, 2013.

Santos, B. de S. A pequena agricultura e as ciências sociais. Revista Crítica de Ciências Sociais, 7/8, 559-563, dez. 1981. Disponível em: http://hdl.handle.net/10316/10791

Santos, B. de S. Construindo as epistemologias do SulAntologia Essencial Volume I: para um pensamento alternativo de alternativas. Ciudad Autónoma de Buenos Aires: CLACSO, 2018.

Santos, E. L.; Braga, V.; Souza, R.; Braga, A. Desenvolvimento: um conceito multidimensional. Revista Desenvolvimento Regional em Debate, ano 2, 1, 44-61, jul. 2012. Disponível em: http://hdl.handle.net/10400.22/1858

Schistek, H. O semiárido brasileiro: uma região mal compreendida. In: Conti, I. L.; Schroeder, E. O. (Orgs.). Convivência com o Semiárido brasileiro: autonomia e protagonismo social. Brasília: IABS, 2013. p. 31-43.

Schroeder, E. O.; Alves, G. G.; Mazzini, V. L. O desafio de valorizar e difundir o conhecimento do semiárido. In: Conti, I. L.; Schroeder, E. O.; Medaglia, V. R. Construindo saberes, cisternas e cidadania: formação para a convivência com o semiárido brasileiro. Brasília: IABS, 2014. p. 27-42.

Shiva, V. Abrazar la vida: mujer, ecología y desarrollo. Madrid: Horas y Horas, 1995.

Shiva, V. Monoculturas da mente: perspectivas da biodiversidade e da biotecnologia. São Paulo: Gaia, 2003.
Silva, R. M. A. Entre o combate à seca e a convivência com o semiárido: transições paradigmáticas e sustentabilidade do desenvolvimento. Brasília, Tese (Doutorado em Desenvolvimento Sustentável) - UnB, 2006.

Silva, V. R. D. Pluriatividade e sustentabilidade em comunidades rurais do Semiárido nordestino. Recife, Dissertação (Mestrado em Desenvolvimento e Meio Ambiente) - UFPE, 2015.

Silva Jr., W. A. O coronelismo em Salgueiro: uma análise da trajetória política do coronel Veremundo Soares (19201945). Recife, Dissertação (Mestrado em História) - UFPE, 2006.

SUDENE - Superintendência do Desenvolvimento do Nordeste. Uma política de desenvolvimento econômico para o Nordeste. 2. ed. Recife: GTDN, 1967.

TED. O Perigo de uma História Única: Chimamanda Adichie. TED Ideias Worth Spreading, 2009. Vídeo (19 min). Disponível em: $<$ https://www.ted.com/talks/chima-manda_ngozi_adichie_the_danger_of_a_single_story $>$. Acesso em: 06 abr. 2020.

Torres, D. X.; Lemos, G. T. A trajetória da oferta de educação escolarizada para os povos campesinos: sujeitos processos e proposições. In: Anais do Encontro de Pesquisa Educacional de Pernambuco. Caruaru, 2012.

Walsh, C. Interculturalidad, plurinacionalidad y decolonialidad: las insurgencias político-epistémicas de refundar el Estado. Tabula Rasa, Bogotá, 9, 131-152, jul.-dic. 2008.

Whitaker, D. C.; Bezzon, L. C. A cultura e o ecossistema: reflexões a partir de um diálogo. Campinas/SP: Alínea, 2006.

Woortmann, E.; Woortmann, K. O trabalho da terra: a lógica e a simbólica lavoura camponesa. Brasília: Editora UNB, 1997.

Woortmann, E.; Woortmann, K. Velhos camponeses. Revista Humanidades - Terceira Idade, Brasília, 46, 132-141, 1999. 